\title{
Die osteuropäischen Volkssagen vom vorherbestimmten Schicksal
}

\author{
Von ROLF WILH. BREDNICH
}

Von allen Menschheitsfragen überhaupt sind wohl die um Geburt und Tod die ursprünglichsten. Geburt und Tod sind die großen elementaren Ereignisse im Leben des Menschen, sie sind die Pole, zwischen denen sein Dasein verläuft. Geburt und Tod sind gleichzeitig die Einfallstore des jenseitigen Seins für den primitiven Menschen, und es ist natürlich, daß die Vorstellungen und Bilder, die er für jenes andere Sein gefunden hat, um diese beiden Phänomene kreisen.

Dies gilt auch für den Glauben an ein vorherbestimmtes Schicksal. Nach volkstümlicher Vorstellung greifen die Schicksalsmächte schon bei der Geburt eines neuen Erdenbürgers in dessen Leben ein und bestimmen ihm sein Geschick und alles, was ihm im Leben begegnen wird, aber vor allem auch seinen Tod. So verbinden sie mit ihrem Spruch die beiden elementaren Ereignisse des Lebens miteinander. In der Geburt, am Beginn des Lebens, wird so schon der Tod sichtbar.

Der Gedanke liegt nahe, daß sich diese elementaren Vorstellungen vom vorherbestimmten Geschehen auch im Volksglauben und in den Volkserzählungen niedergeschlagen haben. Mehr oder weniger deutlich ausgeprägt finden wir fast in ganz Europa die Vorstellung von der Prädestination alles Geschehens, als dunkle Ahnung oder als vollkommen fest ausgebildeter Volksglaube mit bestimmten Schicksalsgestalten, die das menschliche Geschick in Händen halten und verwalten. Da sich der Volksglaube gewöhnlich sehr gut in den entsprechenden Volkserzählungen spiegelt, war es methodisch wohl gerechtfertigt, die europäischen Märchen, Sagen und Legenden als Grundlage zu nehmen und sich ausgehend von diesem volkskundlichen Material eine Übersicht über die Bedeutung des Schicksals zu ver$7^{-654218 \text { Ringgren }}$ 
schaffen. Hierbei muß betont werden, daß der gesamte Bereich der europäischen Volkserzählungen in die Untersuchung mit einbezogen wurde, also auch alle Gattungen. Es genügt nicht, vom Schicksalsglauben im Märchen oder in der Sage allein zu sprechen. Bei der Betrachtung der Rolle des Schicksals in der mündlichen europäischen Volkstradition ergibt sich die überraschende Feststellung, daß die Erzählungen vom vorherbestimmten Schicksal ein einheitlicher Komplex sind, der von der Erzählforschung in seiner Zusammengehörigkeit und Verwandtschaft bisher noch kaum erkannt worden ist.

Der Volksglaube vom vorherbestimmten Schicksal drängt bei den verschiedenen Völkern und zu verschiedenen Zeiten zur Personifikation. Der Ursprung dieser anthropomorph gedachten Schicksalsgestalten liegt in dem Glauben, daß das Leben des Menschen und alles ihn umgebende Geschehen unter dem $Z$ wang von Mächten stehen, die ihm durch mündlichen Spruch bei seiner Geburt alles vorausbestimmt haben, was ihm im Leben widerfährt. Von diesem Glauben ist es nur ein Schritt bis zur Personifikation jener Schicksalsmacht. Gewöhnlich finden wir weibliche Gestalten in der Rolle der Schicksalskünder, weil es immer Frauen sind, die bei der Entbindung und beim Wochenbett der Mutter zur Seite stehen und von eh und je mit Weissagung, Zauber und dgl. in Verbindung gebracht wurden.

Der Volksglaube von den schicksalsverkündenden weiblichen Dämonengestalten, den „Schicksalsfrauen“, ist keine auf die indogermanischen Völker beschränkte Vorstellung. Schon die altägyptische Religion kannte in den sieben Hathoren ausgesprochene Schicksalsgöttinnen; in den uns überlieferten ägyptischen Märchen treten sie an die Wiege neugeborener Kinder und bestimmen ihnen das Schicksal voraus. Der Volksglaube von den schicksalsbestimmenden Gestalten ist heute noch in einigen europäischen Ländern lebendig. Vor allem sind es Länder im Osten Europas, und sie weisen in Bezug auf die Erzähltradition so große Gemeinsamkeiten auf, daß es sich empfiehlt, das Erzählgut und den dazugehörigen Volksglauben im Zusammenhang und als Einheit zu betrachten und sich nicht auf einzelne Länder zu beschränken. Dies bedeutet, daß man das gesamte Balkangebiet von Griechenland bis Rumänien und Jugoslawien, ferner die Tschechoslowakei sowie Litauen und Lettland in die Untersuchung mit einbeziehen muß. Einer solchen großräumigen vergleichenden Betrachtungsweise stehen 
naturgemäß nicht wenige Schwierigkeiten entgegen. Sie sind zunächst rein sprachlicher Natur, aber es darf nicht vergessen werden, daß es auf dem Gebiet des Schicksalsglaubens für eine übernationale Betrachtung der Überlieferungen noch kaum Vorarbeiten oder Quellenpublikationen gibt. ${ }^{1}$

Überall in Europa war der Glaube an die Schicksalsfrauen im ausgehenden I9. Jahrhundert noch 1ebendig. Zuerst wird man an die Griechen denken müssen, die ja schon im Altertum die Personifikation der Schicksalsmacht in weiblicher Gestalt kannten. Die Moira der nachhomerischen Zeit hat im Volksglauben jahrhundertelang weitergelebt und ist auch im 2o. Jahrhundert noch hier und da ein Charakteristikum der neugriechischen Vorstellungen vom vorherbestimmten Schicksal geblieben. Wir stehen hier vor einem religionsgeschichtlich ziemlich einmaligen Beispiel von Kontinuität über viele Jahrhunderte. Kein Wunder, daß die ersten Forschungsreisenden, denen dieser Glaube im neuzeitlichen Griechenland begegnete (z. B. John Galt, Pouqueville, Wordsworth, Wachsmuth, James Th. Bent, L. Heuzey u. a.) ihren Ohren kaum trauen wollten. Denn für lange Jahrhunderte waren die Moiren im Dunkel der Geschichte untergetaucht, während derer sie indessen im Volksglauben und in der Volkserzählung eine bedeutende Rolle gespielt haben müssen.2 Von den Griechen ist die Vorstellung nach dem Norden gekommen; hier haben die Albaner ${ }^{3}$ und die Rumänen ${ }^{4}$ unter dem Namen Miren, Fata und Ursitori die Schicksalsgestalten übernommen und mit dem einheimischen Volksglauben vermischt. Den südslawischen Völkern war - vermutlich seit urslawischer Zeit - die Vorstellung von einer weiblichen Geburtsgottheit (Roždanica) gemeinsam. Der Glaube von den schicksalsbestimmenden Frauengestalten verband sich mit dem von der Geburtsgöttin und bestimmt auch heute noch die volkstümlichen Vorstellungen der Bulgaren, Serben, Kroaten, Slowenen, Tschechen und Slowaken vom

1 Meine Studien zu den europäischen Volksüberlieferungen vom vorherbestimmten Schicksal sind erschienen unter dem Tite1 „Volkserzählungen und Volksglaube von den Schicksalsfrauen", Helsinki r964 (Folklore Fellows Communications 193).

2 Bernh. Schmidt, Das Volksleben der Neugriechen und das hellenische Altertum, Leipzig I87I, S. 213 ff. und Albert Thumb, ,Zur neugriechischen Volkskunde I. Die Schicksalsgöttinnen im neugriechischen Volksglauben", Zeitschrift für Volkskunde 2, I892, S. 123-I34.

3 Georg Stadtmüller, ,Altheidnischer Volksglaube und Christianisierung in Albanien", Orientalia Christiana Periodica 20, I954, S. 2 I I ff.

4 S. Fl. Marianŭ, Nascerea la Români. Studiŭ etnograficŭ, București ı892, S. I ff. 
Schicksal. ${ }^{1}$ Bei den Polen und Russen ist der heidnische Schicksalsglaube weitgehend von der christlichen Idee der Vorsehung verdrängt worden. Bestimmte Schicksalsgestalten sind in Polen und Rußland gegenwärtig nicht mehr nachzuweisen. - Die Schicksalsfrauen sind bei den genannten Völkern göttergleiche unsterbliche Wesen, aber sie tragen in starkem Maße auch anthropomorphe Züge. Sie sind keineswegs frei von menschlichen Empfindungen, Leiden und Schwächen. Oft werden sie geschildert als leicht reizbare und empfindliche Wesen, die jede Nachlässigkeit und Vergeßlichkeit bestrafen. Krankheiten sind sie unterworfen, Schmerz und Wut empfinden sie genau wie Menschen. Aber sie sind auch mit etwas Aufmerksamkeit leicht zufriedenzustellen und zu einem günstigen Spruch zu bewegen. Die Güte der ihnen als Opfer vorgesetzten Speisen und Getränke entlockt ihnen gute Segenswünsche und Voraussagen für das Kind. In den erwähnten südosteuropäischen Ländern glaubt das Volk, daß sich bei der Geburt eines Menschen die Schicksalsfrauen einstellen und über alle wichtigen Ereignisse seines Lebens bestimmen. Sie sagen die Zahl seiner Lebensjahre voraus, den frühen Tod, insbesondere ein jähes, gewaltsames und unerwartetes Lebensende, seinen künftigen Beruf, Reichtum und Armut, und sie bestimmen den Ehepartner. Volkstümlicher Glaubensvorstellung entspricht es, daß man die Sprüche dieser Dämonengestalten für endgültig hält, an sie glaubt und sich nach ihnen richtet. Jeglicher Versuch, den einmal bestimmten Gang der Dinge zu ändern, wäre von vornherein vergebens und würde nur dazu führen $\mathrm{da} ß$ das Vorherbestimmte umso unausweichlicher eintritt. Bei der Besprechung der volkstümlichen osteuropäischen Schicksalserzählungen werden wir zahlreiche Beispiele für diesen stark fatalistisch anmutenden Volksglauben kennenlernen.

Bevor wir zu diesen Volkserzählungen übergehen, ist noch ein kurzer Blick auf die übrigen europäischen Länder notwendig. Verwandte Vorstellungen von den Schicksalsfrauen finden wir auch bei den Letten und Litauern in Nordosteuropa. Bei ihnen hat die Göttin Laima die Schicksalsfunktion inne, und sie oder die aus dieser Vorstellung entwickelte Dreiheit der Laimen tauchen in Volkserzählungen und Volksliedern (Dainas) immer

1. F. S. Krauß, „Sreća. Glück und Schicksal im Volksglauben der Südslawen“, Mitteilungen der Anthropologischen Gesellschaft in Wien $16,1886,102 \mathrm{ff}$. 
wieder als die Verwalterinnen des menschlichen Schicksals auf. Ich übergehe die Diskussion um den Ursprung der baltischen Laima und verweise auf die einschlägigen Arbeiten von Haralds Biezais. ${ }^{1}$ Bei den germanischen Völkern ist der Glaube an die schicksalsbestimmenden Frauengestalten (Nornen, Völven) heute so gut wie ausgestorben; Zeugnisse für ein Weiterleben dieses Vorstellungskreises sind - außer in Island - sämtlich historischer Art. Nur in der deutschen Sprachinsel Gottschee in Jugoslawien hat man in den letzten Jahrzehnten noch Überlieferungen von großer Altertümlichkeit aufgefunden, die darauf schließen lassen, daß dort die germanischen Schicksalsfrauen unter dem deutschen Namen Schöpferlein weitergelebt haben. ${ }^{2}$ Allerdings waren dort in der slawischen Umwelt mit dem ausgeprägten Volksglauben von den Rojenice - Sojenice ideale Voraussetzungen für ein Weiterleben der aus dem Mutterland mitgebrachten Vorstellungen gegeben. Der romanischen Völkerfamilie gemeinsam ist der Volksglaube von den Feen; er wurzelt letzten Endes in römischen Vorstellungen, im Glauben an die Parzen und an die Fata. Aber der Feenglaube der Romanen ist heute so differenziert und hat so verschiedenartige Glaubenselemente in sich aufgesogen, daß man die Feen nicht mehr einfach mit den Schicksalsfrauen identifizieren kann. In Frankreich ist die Fee der Märchendämon schlechthin geworden, und die Schicksalsfunktion ist nur eine von vielen Funktionen, welche die Fee ausübt. Außerdem fehlt hier im Westen-rein geographisch betrachtet-der Zusammenhang mit den osteuropäischen Volkserzählungen, denen wir uns jetzt zuwenden wollen.

Im Sinne von C. W. von Sydow bilden die Erzählungen, die sich als Ergebnis meiner Untersuchungen zum volkstümlichen Schicksalsglauben herausgeschält haben, eine neue und nach systematischen Gesichtspunkten zusammengehörige Gruppe, die „Schicksalserzählungen“. Ich verstehe darunter die Volkserzählungen vom vorherbestimmten Schicksal, d. h. Märchen und Sagen, in denen einem Menschen ein bestimmtes Schicksal prophezeit wird, das unweigerlich eintreten muß. Diese Gruppe ist bisher als eigenständige Erzählüberlieferung von begrenzter geographischer Verbreitung kaum erkannt worden. In den älteren Märchentypenverzeichnissen von Antti

1 Haralds Biezais, Die Hauptgöttinnen der alten Letten, Uppsala I955.

2 Richard Wolfram, „Die Schöpferlein”, Gahrbuch für Volkskunde der Heimatvertriebenen I, Salzburg 1955 , S. $77 \mathrm{ff}$. 
Aarne und Stith Thompson sind diese Erzählungen noch sehr unbefriedigend berücksichtigt. Erst die zweite Revision des Verzeichnisses hat Abhilfe geschaffen. ${ }^{1}$ Allerdings ist hier wiederum zu fragen, ob die Schicksalserzählungen überhaupt in einem Verzeichnis der Märchentypen richtig am Platze sind. Die meisten der hierhergehörigen Volkserzählungen sind keine Märchen; vielmehr handelt es sich um Sagen mit starkem Wirklichkeitsbezug und enger Bindung an den Volksglauben.

Die osteuropäischen Sagen vom vorherbestimmten Schicksal sind einander in Aufbau und Motivbestand sehr ähnlich. Meistens ist das Schicksalskind ein Knabe. Die Schicksalsgestalten erscheinen bei seiner Geburt an der Wiege und sagen dem neugeborenen Kind voraus, durch welchen Umstand es seinen Tod finden wird: Es sind in der Regel außergewöhnliche, bemerkenswerte Todesarten, Unglücksfälle und Katastrophen mannigfacher Art, die zum Gegenstand der Prophezeiung gemacht werden. Das normale Lebensende, der Tod durch Altersschwäche oder Krankheit, ist nur selten der Inhalt des Spruchs der Schicksalsfrauen. Der zweite gemeinsame Zug der Schicksalssagen ist das Motiv, daß die Eltern des Schicksalskindes den Spruch mit anhören oder durch einen anderen Zeugen der Schicksalsverkündung Kenntnis davon erlangen. Ihr ganzes Bemühen ist von dem Tag an auf die Vereitelung des Schicksalsspruches gerichtet. Sie behüten ihr Kind sorgsam, verstecken es in einem unterirdischen Keller oder sperren es in einen gläsernen Turm. Doch das Schicksal läßt sich nicht bezwingen. Am Ende muß der Mensch die Ohnmacht und die Zwecklosigkeit seiner Bemühungen erkennen. Ursprünglich werden wohl alle Schicksalssagen im tragischen Ausgang übereingestimmt haben. Erst in jüngerer Zeit ist bei dem einen oder anderen Sagentyp durch den Einfluß christlicher Gedankengänge ein glücklicher Schluß eingefügt worden, wobei Gott über die Schicksalsfrauen die Oberhand behält. Diese Verchristlichung der Schicksalserzählungen hat jedoch den ursprünglich heidnischen Gehalt nicht beseitigt, sondern lediglich überdeckt. Im Volke selbst ist in Osteuropa der Glaube an die Schicksalsfrauen und der christliche Glaube kein Gegensatz, ja verschiedentlich werden die Schicksalsfrauen sogar als Wesen betrachtet, die von Gott

\footnotetext{
${ }^{1}$ Stith Thompson, The types of the folktale. Antti Aarne's Verzeichnis der Märchentypen translated and enlarged. Second revision, Helsinki $196 \mathrm{I}$ (Folklore Fellows Communications $\mathbf{1} 84$ ).
} 
mit der Schicksalsbestimmung beauftragt worden sind und gegen deren Spruch deshalb Gott selbst und alle Heiligen machtlos sind.

Die folgende Erzählung soll dafür als Beispiel dienen und gleichzeitig einen Eindruck von einer osteuropäischen Schicksalserzählung vermitteln. Die Aufzeichnung stammt aus Bulgarien, die darin auftretenden Schicksalsfrauen heißen Urišnicen.

Als der Herr noch auf Erden wandelte, kam er gegen Abend in das Haus eines Schäfers, wo er über Nacht verblieb. Des Schäfers Frau hatte vor zwei Tagen einen Knaben geboren, und nun war dies die dritte Nacht. Die Urišnicen kamen zum Kinde und bestimmten ihm folgendes: „Durch einen Tropfen Wasser soll er sterben!“ Gott hörte die Worte der Urišnicen und sprach zu ihnen: „Nicht wahr, ihr könnt mir eine Seele nehmen?“ Und sie versetzten: ,Nicht jetzt, sondern wenn er Hochzeit hält, damit ihn seine Mutter und seine Braut beweine!" Und der Herr wurde Taufpate des Kindes, und als er von dannen ging, sprach er zu dem Schäfer: „Wenn ihr einst den Burschen verheiratet, so ladet auch mich, wenn ich lebe, zur Hochzeit, und geht ja nicht ohne mich, um die Braut abzuholen!" Der Schäfer versetzte: „Aber Gevatter, woher sollen wir dich rufen lassen?" Der Herr antwortete: „Einen Kuchen und eine Flasche Wein steckt in eine Tasche und stellt dieselbe auf einen Berg; wenn ich die Tasche sehe, dann komme ich gleich." Der Schäferssohn wuchs heran, und seine Eltern verlobten ihn, und als das Hochzeitsfest anfing, da luden sie auch den Gevatter ein, so wie er es ihnen aufgetragen hatte. Er kam und ging auch mit, die Braut abzuholen, die in einem jenseits des Flusses gelegenen Dorfe wohnte. Sie kamen hin, holten die Braut ab, und als sie zurückkehrten, da war der Fluß angeschwollen; der Herr aber setzte den Bräutigam hinter sich aufs hohe Roß und überschritt so mit ihm den Fluß. Als sie aus dem Wasser stiegen, spritzte ein Tropfen Wasser dem Burschen in den Mund, und er begann davon zu sterben. Alle fingen an zu weinen, besonders die Braut. Gott konnte des Burschen Seele von den Urišnicen nicht retten. Da griff er in seinen Busen und zog ein großes Buch hervor, in welchem die Lebensiahre aller auf Erden lebenden Menschen verzeichnet waren. Dem Burschen waren sechzig, der Braut hundert Jahre bestimmt. Da sagte der Herr, daß wenn die Braut die Hälfte ihrer Lebensjahre den Urišnicen geben wolle, dann würden diese dem Burschen die Seele zurückgeben. Die Braut opferte die Hälfte ihrer Lebensjahre, und der Bursche erhielt seine Seele zurück und blieb am Leben. Was die Urišnicen in der dritten Nacht nach der Geburt bestimmen und ins große Buch eintragen, das kann selbst der Herr nicht abändern.1

Diese Erzählung beschreibt deutlich die Macht, die die Schicksalsfrauen in Händen halten. Selbst Gott muß sich ihnen beugen. Das Motiv vom

1 Adolf Strauß, Die Bulgaren. Ethnographische Studien, Leipzig r898, S. r78. 
Geschenk der Lebensjahre und der treuen Ehefrau hat schon antike Wurzeln und geht auf den altgriechischen Stoff von Admet und Alkestis zurück. ${ }^{1}$ Noch deutlicher wird dieser Zusammenhang der heutigen osteuropäischen Schicksalserzählungen mit der griechischen Antike bei einem anderen bekannten Stoff. Es handelt sich um die Sage von Meleagros, die bei mehreren altgriechischen Autoren in unterschiedlicher Gestalt überliefert wird. Uns interessiert hier die nachhomerische Ausprägung des Stoffes, die etwa folgenden Inhalt gehabt hat:

Einmal schlief Althaea, die Tochter des Thestis, mit Oineus und Mars. Sie zeugten ihren Sohn Meleagros. Bei seiner Geburt erschienen die drei Moiren Klotho, Lachesis und Atropos im Zimmer und spannen ihm sein Schicksal zu. Die erste Moira sagte ihm eine große Zukunft voraus, die zweite wünschte ihm Tapferkeit und Stärke, aber die dritte erblickte das Herdfeuer und rief: ,Ich will, daß dieses Kind nicht länger lebt, wie dieses Holzscheit im Feuer brennt. In dem Augenblick, wenn es verlöscht, soll das Kind sterben." Seine Mutter Althaea, die das alles gehört hatte, sprang aus dem Bett, löschte das Holzscheit und verbarg es auf dem Boden einer Truhe. Der Junge wuchs heran und ging eines Tages mit dem Bruder seiner Mutter zur Jagd. Bei der Rückkehr stritten die Männer über die Verteilung der Jagdbeute, worauf der Junge im Jähzorn seinen Onkel erschlug. Als die Mutter vom Tod ihres Bruders vernahm, holte sie das halbverbrannte Holzscheit aus der Truhe und warf es ins Feuer. Als es verbrannt war, fiel ihr Sohn tot zur Erde.

Diese antik-griechische Erzählung muß in der volkstümlichen Überlieferung der südlichen Balkanhalbinsel tiefe Wurzeln geschlagen haben, denn verschiedenen Märchensammlern unseres Jahrhunderts war es möglich, die Meleager-Geschichte als lebenskräftige Volkserzählung unserer Tage aus dem Volksmund aufzuzeichnen. Sogar in Ätolien, der antiken Heimat Meleagers mit dem kalydonischen Eber, ist die Erzählung mehrfach aufgetaucht, ferner auf Zypern, in Makedonien, in der Türkei in der Gegend von Ankara, in Kroatien, bei den Tschuwaschen, den Letten und Litauern, schließlich auch noch in den Vogesen und in der spanischen Landschaft Katalnien. ${ }^{2}$ Verschiedene Motive der alten Sage sind bis in die Gegenwart fest und unwandelbar geblieben. Dazu zählt vor allem das Motiv von der Schicksals-

1 Georges A. Megas, „Die Sage von Alkestis“, Archiv für Religionswissenschaft 30 , I933 S. I-33.

${ }^{2}$ Johannes Th. Kakridis, Homeric researches, Lund 1949 (Skrifter utgivna av Kungl. Humanistiska Vetenskapssamfundet i Lund 45). Nachträge bei Brednich, $F F C$ I93, S. $17 \mathrm{ff}$. 
vorhersage. Ohne diesen Zug ist die Sage kaum denkbar, in ihm haben wir das konstitutive Bauelement der Sage zu sehen. Die Erzählung lebt geradezu aus dem Spannungsbogen von Voraussage und Erfüllung. Es ist verständlich, $\mathrm{da} ß$ sich der Stoff vorwiegend in solchen Ländern erhalten konnte, in denen die entsprechende Vorstellung von den Schicksalsfrauen noch lebendig ist. In allen anderen Gebieten, in welchen eine solche volksglaubensmäßige Fundierung der Sage nicht mehr vorhanden ist oder nie bestanden hat, wird der Stoff entweder verschwunden sein oder aber nie festen Fuß gefaßt haben. Aus dieser Tatsache wird auch einsichtig, warum die Volkserzählungen vom vorherbestimmten Schicksal in der Regel auf das osteuropäische Gebiet mit dem lebendigen Glauben von den Schicksalsfrauen beschränkt geblieben sind. - Der Schluß der Erzählung von Meleagers Tod hat im Verlaufe der Jahrhunderte manche Abwandlungen und Änderungen erfahren. Nur noch in zwei der zwanzig insgesamt bekannt gewordenen Varianten ist es die Mutter, die den Sohn durch Verbrennen des Scheites tötet. In anderen Fassungen sind es ein Nachbar, der Vater oder die Schwiegermutter des Helden oder der Held selbst, die mit Vorbedacht oder aus Nachlässigkeit und Unkenntnis das Holz verbrennen. In einer Gruppe von Varianten bringt die eigene Frau ihren Mann um, indem sie das Scheit ins Feuer wirft und $i$ hn für seine an ihr begangene Untreue straft. In einer Aufzeichnung aus Žepču in Kroatien wird folgendes berichtet:

Bei einer Geburt wurde eine Frau einmal schwer krank. Ihr Mann war in der Wassermühle, und sie lag zu Hause halb in Ohnmacht und gebar einen Knaben. Spät nachts kehrte der Mann aus der Mühle zurück, kam vor sein Haus und hörte darin ein Flüstern. Zwischen den Balken spähte er ins Haus und erblickte neben dem Fenster drei Frauen wie Vilen in weißen Gewändern. Die eine sagte: „Was wollen wir bestimmen?“ Darauf die andere: „Er soll arm sein, aber er soll lange leben.“ Die beiden anderen antworteten: „Was soll er leben, wenn seine Mutter sowieso schnell sterben wird? Er soll auch sterben, sobald das Holzscheit im Feuer verbrennt". In diesem Augenblick verschwanden sie. Es waren die drei Sojenice, die gekommen waren, das Schicksal des Kindes zu bestimmen. Der Mann ging ins Haus hinein, erblickte das Kind beim Feuer, rief die Frau, und da sie in Ohnmacht und Schmerzen dalag, wußte sie nichts. Er nahm das Scheit, löschte es, trug es in eine Truhe und verschloß sie. In dieser Nacht starb die Frau, und der Vater gab das Kind in die Nachbarschaft zu einer Frau, die das Kind ernähren sollte. Als das Kind etwas größer war, gab sie es dem Vater zurück. Dieser wachte über das Kind, aber als es erwachsen war, wurde es ein händelsüchtiger Trunkenbold. Als dem Vater die 
Klagen der Nachbarn über den Sohn zuwider wurden und die Schande ihn betroffen machte, nahm er das Holzscheit aus der Truhe und legte es ins Feuer, um zu sehen, ob es dem Sohn schaden würde. In diesem Augenblick rief ihm jemand $z u$, daß seine Rinder ins Getreide gegangen seien. Er eilte hinaus, um sie zurückzutreiben. Der Sohn stieß mit dem Fuß das Holzscheit in die Flammen, und als der Vater zurückkam, fand er das Holzscheit verbrannt und den Sohn tot. ${ }^{1}$

Der französische Zigeunererzähler Matéo Maximoff hat den Stoff der Meleagersage aus volkstümlicher Zigeunerüberlieferung aufgegriffen und zu einem Zigeunerroman verarbeitet, der einen bemerkenswerten Erfolg verzeichnen konnte und unter dem Titel „Die Ursitory“ in mehrere Sprachen übersetzt worden ist. ${ }^{2}$

Eine weitere antike Sage, die die Unabwendbarkeit des vorherbestimmten Schicksals zum Thema hat, ist die Überlieferung von König Ödipus, die in dem Drama von Sophokles ihr großes Denkmal gefunden hat und weltweite literarische Verbreitung erfuhr. In der Forschung wird heute allgemein angenommen, daß Sophokles in seinem „Ödipus auf Kolonos" Teile alter Volkssagen verarbeitet und für die Bühne dichterisch gestaltet hat. Spuren der Ödipussage sind bis heute in der osteuropäischen Volksüberlieferung erhalten. Darüber hinaus aber war das christliche Mittelalter genau wie das Altertum sehr reich an volkstümlichen Legenden und Erzählungen, die das Inzestmotiv in seinen vielfältigen Ausprägungen behandeln. Ja, es gibt eine derartige Fülle von Legenden, Dichtungen, Bearbeitungen und Übersetzungen, daß man hier vor einer kaum entwirrbaren Fülle von Material steht. Bevor man eine volkstümliche Inzesterzählung in die Nachfolge des Ödipusstoffes einordnet, ist eine gewissenhafte Prüfung der möglichen Abhängigkeiten erforderlich. In der Vergangenheit hat man sehr großzügig und unbesehen alles für Ödipusvarianten angesehen, was auch nur entfernt mit „Inzest“ und „Sphinx“ zu tun hatte. Viele Belege scheiden bei näherem Zusehen als Ableger mittelalterlicher Legenden aus. Solche Legenden, die nach dem Vorbild des Ödipusstoffes gearbeitet sind und ihrerseits wiederum ins Volk zurückgewirkt haben, sind beispielsweise

1 Tomo Dragičević, „Narodne praznovjerice“, Glasnik Zemaljskog muzeja u Bosne i Hercegovini 20, 1908, S. $45 \mathrm{r}$.

2 Matéo Maximoff, Les Ursitory, Paris 1947; vgl. dazu Rolf Wilh. Brednich, „Les sources folkloriques du roman tsigane 'Les Ursitory' de Matéo Maximoff“ Études tsiganes 9 , r 963 , H. I, S. $5^{-16}$. 
die Legenden von Judas Ischariot, vom hl. Andreas, die Gregoriuslegende oder die Legende vom Elternmörder. ${ }^{1}$ Nur vereinzelte Varianten bleiben übrig, bei denen ein ungebrochener Zusammenhang mit der Antike wahrscheinlich anzunehmen sein wird. Hierzu zählt z. B. eine von F. S. Krauß veröffentlichte Volkserzählung aus Montenegro, die folgenden Inhalt hat:

Eine Frau hört bei ihrer Niederkunft die Unterhaltung zweier Vilen über das Schicksal ihres neugeborenen Kindes: Es sei zu einer unglücklichen Stunde geboren, es werde der Gatte seiner eigenen Mutter werden. Nach der Geburt des Knaben nimmt die Frau ein Nädelchen zur Hand, fädelt einen Seidenfaden ein und zieht ihn dem Knäblein durch beide Fersen hindurch. Dann hängt sie ihn auf einem Tannenbaum auf. Ein Kaiser kommt auf der Jagd durch den Wald und findet das Kind. Er bringt es seiner Frau mit nach Hause; es wird am Hof großgezogen.

Als der Knabe von seiner Herkunft erfährt, zieht er von dannen und übernachtet in einer Herberge, bei seiner Mutter. Sie war noch jung und rüstig, der Jüngling gefiel ihr gut, und sie sagte zu ihm: „Hör mal, Bursche, wenn es dir paßt, so heiraten wir!" Damit war er einverstanden, und sie heirateten am nächsten Morgen. Nach der Trauung begab sich der junge Mann auf die Jagd. Abends kehrte er in Schweiß gebadet nach Hause zurück und zog seine Schuhe aus. Die Frau starrte entsetzt auf seine nackten Füße und erinnerte sich dabei an das, was die Vilen einst bei ihrer Niederkunft verkündet hatten. Als der Sohn die grausige Wahrheit erfuhr, sprang er auf der Stelle auf, sattelte sein Roß und rief aus: „Beim Allah, Mutter, deine Augen werden mich nimmermehr wiedersehen!" So zog er in die unbekannte Welt, sie erhielt aber nie mehr Kunde von ihm.1

Bei dieser Variante dürfen wir wohl zu Recht von einem Zusammenhang mit dem antiken Stoff reden, zumal das Motiv von den durchschnittenen Füßen, das Ödipus seinen Namen gegeben hat, noch eine deutliche Sprache spricht.

Eine andere - bisher nicht typenmäßig erfaßte — osteuropäische Volkserzählung vom vorherbestimmten Schicksal ist die Sage vom prophezeiten Tod durch einen Wolf. In ihr spiegelt sich besonders deutlich jener Fatalismus, der im unwiderruflichen Eintreffen des verhängten Schicksalsspruches zum Ausdruck kommt. Besonders bemerkenswert ist außerdem die Vielfalt der Möglichkeiten, die die Erzähler in den verschiedenen Ländern zur Aus-

1 Zu letzterer vgl. Rolf Wilh. Brednich, ,Die Legende vom Elternmörder in Volkserzählung und Volksballade", Gahrbuch für Volksliedforschung 9, 1964, S. 116143.

2 Fr. S. Krauß, ,Die Ödipussage in südslawischer Volksüberlieferung“, Imago 2I, I 935 , S. $35^{8-360 .}$ 
gestaltung dieser Sage gefunden haben. Ihre Grundform ist recht einfach: Die Schicksalsfrauen sagen einem neugeborenen Kind voraus, es werde durch einen Wolf sein Ende finden; eines Tages, als das Kind erwachsen ist, erscheint zur vorherbestimmten Zeit der Wolf und verschlingt den Jüngling. Dieser angenommenen Grundform entsprechen heute nur noch sehr wenige Sagenvarianten. Alle anderen sind durch sekundäre Komplizierungen und epische Erweiterungen in ihrem Motivbestand weiter aufgeschwellt worden. Wie bei anderen Sagen vom vorherbestimmten Schicksal gehen diese Erweiterungen größtenteils aus dem Motiv der versuchten Vereitelung des Schicksalsspruches hervor. Meist wird erzählt, die Eltern seien Zeugen des Schicksalsspruches geworden oder haben durch einen Zeugen von der Prophezeiung erfahren. Sie versuchen nun mit aller Macht, das Vorhergesagte zu verhindern und das Kind zu retten. Aber - wie schon vorher betont gerade durch diese Versuche führen sie den Spruch selbst herbei oder helfen bei der Ausführung des Vorhergesagten mit.

Für die verschiedenen Ausgestaltungen der Sage folgen hier einige kurzgefaßte Beispiele.

Eine kroatische Erzählung aus der Gegend von Varaždin erzählt folgendes:

Ein Graf und seine Frau bekamen einen Sohn. Bei der Geburt erschienen die drei Sujenice, um ihm sein Schicksal zu bestimmen. Die erste sagte: „Er soll Offizier werden!“ Die zweite: „Er soll werden, was sein Vater ist!“ Aber die dritte sagte: „Ein Wolf soll ihn auffressen!“ Ein Bettler, der das alles gehört hatte, warnte die Eltern. Sie ließen ihren Sohn in der Schule erziehen. In den Ferien bat er einmal seinen Vater, mit der Kutsche in den Wald fahren zu dürfen. Im Wald wuchsen viele wohlriechende Rosen. Der Knabe bat den Kutscher, ihm eine Blume abzupflücken. Der Kutscher brachte ihm die Blume und schloß die Wagentüre. Als sie nach Hause kamen, eilten Vater und Mutter der Kutsche entgegen, um das Kind herauszuheben. Sie öfneten den Wagen, aber es sprang ein Wolf heraus. Das war also die im Wald gepflückte Rose! Und so war der Spruch der Sujenice in Erfüllung gegangen. ${ }^{1}$

Während der Wolf hier in der Verwandlungsform der Rose erscheint, kommt er in einer serbischen Fassung aus einer Kerze:

Ein reicher Türke übernachtet auf der Reise bei starkem Regen in einem Haus, in dem den Eltern gerade ein Sohn geboren worden war. In der Nacht hörte er die Stimmen der drei Suðenice beraten. Die erste sagte: „Wenn das Kind groß wird, soll

1 M. K. Valjavec, Narodne pripovedke skupio u i oko Varaždinu, Varaždina 1858, S. 90 , Nr. 9 . 
es das Gut von diesem Türken erben.“ Darauf die zweite: „Das Kind soll, wenn es erwachsen ist, ertrinken.“ Die dritte Suðenica bestimmte: „Es soll an seinem Hochzeitstag vom Wolf gefressen werden." $\mathrm{Da}$ die drei sich nicht einigen konnten, riefen sie ihren Herren Uris herbei, der bestimmte, der Spruch der dritten Suðenica solle eintreffen. Der Türke, der dies alles mitgehört hatte, fühlte Mitleid mit dem Kinde, brachte es zur Taufe und suchte später eine Braut. Er baute eine Scheune, untersuchte sie gut, bevor er nach der Hochzeit das Paar hineinließ. Er befahl ihnen, die Kerze brennen zu lassen. Als die beiden Brautleute allein waren, floß aus der Kerze plötzlich eine Wachsträne, begann rasch zu wachsen, wurde zum Wolf, sprang auf den Bräutigam und fraß ihn auf. Darauf verwandelte sich das Untier wieder in die Träne der Kerze zurück. ${ }^{1}$

Viele der in Südosteuropa verbreiteten Schicksalserzählungen sind auch bei den Litauern und Letten heimisch geworden. Dort sagen Laima oder die drei Laimen das Schicksal voraus. Auch die Sage vom prophezeiten Tod durch einen Wolf findet sich dort. In einer lettischen Fassung aus Siuxt aus der Sammlung von Lerchis-Puschkaitis wird folgendes erzählt:

Laima sagt einem neugeborenen Bauernsöhnlein voraus, daß es später einmal durch einen Wolf umkommen werde. Als der Junge erwachsen und Bauer geworden ist, fährt er in die Stadt, weil er meint, daß er dort vor Wölfen sicher sei. Unterwegs nimmt er eine Frau in seinem Wagen auf, die mit ihm in die Stadt fahren will. Sie verwandelt sich in eine Wölfin und zerreißt den Bauern. ${ }^{2}$

Auch hier haben wir wieder das unerbittliche Walten des vorherbestimmten Schicksals! Hier und da ist dieser tragische Gehalt der Schicksalserzählungen auch schwankhaft überdeckt, aber der heidnische Untergrund wird doch noch recht deutlich, wie aus der folgenden Variante, ebenfalls aus Lettland, zu entnehmen ist. Die Einleitung ist ins Schwankhafte gewendet und erzählt, wie es einem Mädchen namens Barbara gelingt, den Inhalt des Laimenspruches über ihr künftiges Schicksal zu erfahren.

In alten Zeiten pflegten Gott und Laima auf Erden zu wandeln, so daß ihnen Menschen begegnen konnten. Einmal wandte sich das Mädchen Barbara an Gott, um ihn um einen Mann zu bitten. Gott antwortete: „Ich kann dir, liebes Mädchen, nur Gesundheit geben, einen Mann kann dir nur Laima bescheren. Wenn du den Spruch hören willst, den Laima über dich gegeben hat, so folge mir." Barbara ging mit Gott

1 Veselin Čajkanović, Srpske narodne pripovetke, Beograd 1927 (Srpski etnografski zbornik 4I), S. 307 f., Nr. 87.

2 A. Lerchis-Puschkaitis, Latweeschu tautas pasakas, Bd. 2, S. 84. 
zu Laima und wartete im Vorraum, während Gott, der sich betrunken stellte, hineintaumelte. „Lieber Gott, Väterchen“, rief Laima, von ihrem Stuhl aufspringend, ,wo hast du dich angetrunken?“ - „Auf Barbaras Hochzeit“, antwortete er. „Ich habe aber doch der Barbara keinen Mann bestimmt; ich habe ihr doch bestimmt, eine alte Jungfer zu werden und von den Wölfen aufgefressen zu werden.“ - „Da hörst du, Mädchen, was Laima dir bestimmt hat", sagte Gott, indem er zu Barbara hinaustrat. ,,So wird es auch geschehen!“ Barbara bat ihren Bruder, sie nicht zur Weide zu schicken, da Wölfe sie dort fressen könnten. Der Bruder gewährte ihr die Bitte und behütete sie bis zu ihrem Tode in seinem Höfchen. Aber als sie gestorben und begraben war, scharrten Wölfe sie aus dem Grabe und fraßen sie. ${ }^{1}$

Die verschiedenen hier vorgeführten Varianten sind lediglich Abwandlungen eines und desselben Grundgerüstes. Die Gesamtverbreitung dieses Sagentyps weist weit über den europäischen Osten, das eigentliche Zentrum der Erzählung, hinaus. Ein Zusammenhang mit den entsprechenden in Asien verbreiteten Fassungen des Stoffes muß bestehen. Es kann im vorliegenden Fall nicht ohne weiteres entschieden werden, ob es sich hierbei um Sagenwanderung oder um gemeinsame Urverwandtschaft handelt. Jedenfalls sind die außereuropäischen Parallelen den soeben referierten Varianten derart ähnlich, daß polygenetische Entstehung auszuschließen ist. Der einzig greifbare Unterschied ist der, daß statt des Wolfes in Asien ein Tiger erscheint. Die Schicksalsfrauen sind durch andere entsprechende Gestalten mit der Funktion der Schicksalsvorhersage ersetzt. Es folgt der Inhalt einer zentralindischen Erzählung zum Vergleich mit den europäischen Fassungen:

Ein König hatte einen einzigen Sohn. Bei seiner Geburt waren weise Männer zugegen gewesen, welche die Zukunft des Kindes vorher verkündigt hatten: ,Dieser ist nur für kurze Zeit gekommen, denn an seinem Hochzeitstage wird ihn ein Tiger holen." Darum ließen ihn seine Eltern nie in den Wald noch auf die Jagd gehen, und ließen ihn nie allein. Als er Hochzeit machen wollte, machten sie großartige Vorbereitungen. Dann erbauten sie eine Festung, worin er wohnen sollte. Mit großem Pomp ward seine Hochzeit gefeiert. Als er mit seiner Frau in der Sänfte saß, inmitten des Hochzeitszuges, sagte er zu ihr: ,Die Wahrsager haben geweissagt, daß mich am Hochzeitstage der Tiger holen werde, und nun ist alles so glücklich verlaufen." Darauf sprach sie: „Möchtest du gerne mal einen sehen?" Er sprach: „Zeige ihn mir, wenn du kannst." Sie hatten etwas Kuchenteig mitgebracht, der übrig geblieben war. Daraus machte sie in der Sänfte die Form eines Tigers und zeigte ihm das Gebilde. Dies ward im selben Augenblick lebendig, ward zum Tiger.

${ }^{1}$ P. Šmits, Latviešu pasakas un teikas, Bd. 14, Rigā r937, S. 197. 
Der sprang auf den Knaben, packte ihn, sprang mit ihm aus der Sänfte, eilte mit ihm in den Wald und fraß ihn. So ward die Weissagung erfüllt. ${ }^{1}$

In dieser indischen Erzählung kehren alle Elemente der europäischen Schicksalssagen wieder: Die Schicksalsverkündung, der erfolglose Versuch der Eltern, das Unheil aufzuhalten, die Erfüllung des Vorhergesagten, indem der 'Tiger aus seiner Verwandlungsform hervortritt und den Bräutigam tötet.

$\mathrm{Zu}$ den osteuropäischen Volkserzählungen von den Schicksalsfrauen ist auch eine Gruppe von Märchen zu rechnen, die man als Schicksalsmärchen oder Märchen vom vorherbestimmten Schicksal bezeichnen kann. Es handelt sich dabei hauptsächlich um die beiden Märchen „Der reiche Mann und sein Schwiegersohn“ (AT 930) und „Die vorherbestimmte Ehe“ (AT 930A). Beide sind in ganz Europa und darüber hinaus verbreitet und bekannt. Aber in Osteuropa hat sich eine bestimmte Sonderform dieser Erzählungen herausgebildet, die es uns erlaubt, sie an die Seite der Schicksalssagen zu stellen. Beide Märchen sind von Antti Aarne ${ }^{2}$ bezw. Archer Taylor ${ }^{3}$ bereits monographisch untersucht worden. Bei beiden ist der orientalische Ursprung mit einiger Sicherheit erwiesen. Vermutlich von Indien aus haben die Märchen ihre Wanderschaft angetreten, mehrmals nach verschiedenen Richtungen und $\mathrm{zu}$ verschiedenen Zeiten. Auf diese Weise sind sie auch nach dem Südosten Europas gelangt, wahrscheinlich zunächst nach Griechenland. Dort ging jene Umwandlung vor sich, der wir unsere Aufmerksamkeit zuwenden wollen. Wir betrachten zuerst das Märchen vom Reichen Mann und seinem Schwiegersohn, auch bekannt unter Titeln wie Märchen vom Kaufmann Marko, vom Krämer Peter oder vom Glückskind mit dem Todesbrief etc. Es war bereits seiner Entstehung nach Schicksalsmärchen, d. h. es behandelt ein Thema von der Vorherbestimmung und der Erfüllung eines Schicksalsspruches. Einem armen Jungen wird prophezeit, daß er die Tochter eines reichen Mannes heiraten soll. Der reiche Mann hört dies und versucht die Heirat zu verhindern, erreicht aber nichts und stürzt sich am

1 Ferdinand Hahn, Blicke in die Geisteszuelt der heidnischen Kols. Sammlung von Sagen, Märchen und Liedern der Oraon in Chota Nagpur, Gütersloh 1906, S. 61 f., Nr. 32.

"Antti Aarne, „Der reiche Mann und sein Schwiegersohn”, Helsinki I9I6 (Folklore Fellows Communications 23).

${ }^{3}$ Archer Taylor, ,,The predestined wife“, Fabula 2, 1958, S. 45-82. 
Ende selbst ins Unglück. In Indien ist die Geschichte seit dem 3. nachchristlichen Jahrhundert bekannt. Aber in den verschiedenen überlieferten Texten wird mit dem Begriff des Schicksals keine einheitliche Auffassung verbunden, etwa der Gedanke an eine Personifikation. Verschiedene Personen werden darin zum Sprecher des Schicksals gemacht, Brahmanen, Priester, der königliche Hofkaplan, ein Büßer oder auch eine unsichtbare Stimme usw. In Griechenland oder den anderen südosteuropäischen Ländern fand diese Erzählung nun einen Raum vor, in dem der Volksglaube vom vorherbestimmten Schicksal sich in entsprechenden Schicksalsgestalten kristallisiert hat. Die aus dem Orient zugewanderte Erzählung wurde in ihrem Einleitungsmotiv umgebildet und erhielt ihre für den ganzen südosteuropäischen Raum charakteristische Form. In die Funktion der Schicksalskünder traten wie in den heimischen Erzählungen die dem Volksglauben geläufigen Moiren ein und bewirkten, daß das zugewanderte Märchen nicht mehr als Fremdkörper empfunden wurde, sondern ganz den Eindruck einer bodenständigen Erzählung macht. Auf gleiche Weise wuchs das Märchen auch in das Erzählgut der benachbarten nördlicheren Länder hinein, wo es verwandte Vorstellungen vom Schicksal und die gleichen Gestalten des Volksglaubens vorfand. Die südosteuropäischen Varianten des Märchentyps AT 930 mit dem Motiv der Schicksalsbestimmung durch dämonische Gestalten sind untereinander eng verwandt und bilden einen einheitlichen Komplex, der sich deutlich aus dem übrigen Märchenmaterial dieses Typs abhebt.

Wir wählen eine für den südosteuropäischen Bereich typische Variante aus. Es handelt sich um eine Fassung aus Albanien; die Schicksalsfrauen heißen dort wie im Neugriechischen Miren.

Es lebte einmal ein sehr reicher Mann, der auf Reisen ging, um Schafe zu kaufen. Er kam unterwegs zu einem armen Haus, in dem er übernachten wollte, weil es Abend geworden war. Er klopfte an die Tür, trat ein und fand eine arme Frau, die vor drei Tagen einem Knaben das Leben geschenkt hatte. Die Frau nahm den Reisenden auf, bereitete ihm ein Lager und wünschte ihm eine gute Nacht. Als er aber das Bettzeug sah, scheute er sich davor und hielt es für ratsamer, nicht schlafen zu gehen, sondern setzte sich neben dem Herd nieder und blieb dort sitzen und schlummerte.Gegen Mitternacht wachte er von einem Geräusch auf und sah drei hochgewachsene Frauen eintreten. Das waren die Miren, die am dritten Tage nach der Geburt des Knaben kamen, um ihm sein Schicksal zu bestimmen. Sie setzten sich auf den Fußboden rund um den Tisch, der schön gedeckt war. Alles Silbergeschirr des 
Hauses stand darauf, und in der Mitte befand sich ein Trinkbecher auf einem Teller. Dieser Trinkbecher war mit Honig gefüllt, in dem drei Mandeln für die Miren schwammen. Auf dem Tisch lagen drei Messer, drei Gabeln und drei Mundtücher, ferner standen dort drei Teller mit Essen, und drei Schnitten Brot waren vorhanden. Alles war für die Miren bereitet, die erwartet wurden, um dem Knaben das Schicksal zu beschließen. Der Gast am Herd stellte sich schlafend, denn er wollte sehen und hören, was es da gebe. - Die Miren setzten sich, aßen und tranken, dann nahm die älteste und oberste von ihnen das Knäblein aus der Wiege, wickelte es aus den Windeln und schrieb mit dem Finger auf seine Stirn: ,Die Zeit wird kommen und die Zeit wird vergehen. Der Mann am Herd, der als Gast hier weilt, wird dich zum Gatten seiner Tochter machen.“ Als der Fremde diesen Spruch hörte, war er davon wenig erbaut. Aber er gab keinen Laut von sich und tat weiter, als ob er schliefe. Da erhob sich die zweite Mire, nahm das Kind und schrieb ihm auf die Stirn: „Der Mann am Herd wird Meuchelmörder gegen dich dingen." — Dann schrieb die dritte Mire: „Alles wird sich erfüllen, wie die Schwestern es schrieben. Aber die gedungenen Meuchelmörder werden nicht dich, sondern den Mann dort am Herd erschlagen." - Sie wickelte das Kind wieder in die Windeln, legte es in die Wiege zurück, dann sagten alle drei ,Gute Nacht" und verschwanden. - Der Gast an der Feuerstätte blieb wie versteinert sitzen, wußte nicht, was er tun sollte und sagte zu sich: ,Dieser bettelarme Knabe soll mein Schwiegersohn werden? Nein, das wird nicht geschehen! Durch ihn soll ich sterben? Da schaffe ich lieber rechtzeitig Abhilfe! Morgen früh sage ich der Frau, sie möge mir das Kind geben, damit ich es an Kindes Statt annehme. Was ich dann mit ihm mache, weiß ich schon." - Am nächsten Morgen bat der Fremde vor seinem Aufbruch die Frau, sie möge ihm ihren Neugeborenen überlassen, denn er sei kinderlos und werde den Knaben lieben wie sein eigenes Kind, sie aber sei arm und habe viele Sprößlinge zu nähren. Er bot ihr ferner eine stattliche Geldsumme an, so daß die Mutter auf den Vorschlag einging. Dann machte er sich mit dem Neugeborenen auf den Weg, der ins Gebirge führte, denn auf der Alm wollte er Schafe kaufen. Unterwegs kam er zu einem Felsen, in dem eine Höhle war, in die er das Kind hineinwarf, in der Hoffnung, dort werde sein Weinen von niemandem gehört. Hierauf stieg er weiter zur Bergwiese empor, kaufte die Schafe und machte sich auf den Heimweg, froh, die Erfüllung der Mirensprüche vereitelt zu haben. Schlafend lag das Kind in der Höhle. Bevor es erwachte, ging die oberste der drei Miren auf die Alm, holte von dort die Ziege, welche am meisten Milch gab, führte sie in die Höhle, wickelte das Knäblein aus den Windeln und legte seinen Mund an den Euter des Tieres. Und der Kleine trank; das geschah nun so an jedem Morgen und Abend. Jeden Abend brachte die Mire die Ziege auf die Alm zurück. ${ }^{1}$

1 Laographía I, Athen 1909, S. 93-100, nach der Übersetzung bei Maximilian Lambertz, Zzvischen Drin und Vojusa. Märchen aus Albanien, Leipzig und Wien r922, S. 9-12. 
Bis hierhin möge die wörtliche Erzählung genügen. Das Märchen geht dann in der bekannten Richtung weiter. Der Säugling wird von einem Hirten aufgefunden, aufgezogen und Ziegensäugling genannt. Nach 20 Jahren entdeckt der Reiche erneut den Jüngling, will ihn beseitigen und schickt ihn mit einem Brief zu seiner Frau. Doch hier greift die zweite Mire ein und bringt durch die Abänderung des Briefes die Hochzeit zwischen dem Ziegensäugling und der Tochter des Reichen zustande. Der Mann ruht nicht und will seinen Schwiegersohn ermorden. Doch die dritte und jüngste der Miren erscheint dem Ziegensäugling im Traum und verhindert den Mord. Die gedungenen Meuchelmörder bringen den Reichen selbst um, so daß der Spruch der drei Miren in Erfüllung gegangen ist.

Das zweite Schicksalsmärchen von der vorherbestimmten Ehe ist nach Inhalt, Herkunft und Verbreitung eine genaue Parallele zu der Erzählung vom reichen Mann und seinem Schwiegersohn. Sein Urspung wird ebenfalls in Indien zu suchen sein, wo es seit dem 9. Jahrhundert aufscheint. In Osteuropa hat es im allgemeinen die folgende ökotypische Form angenommen: Ein Mann hört, wie die Schicksalsfrauen einem neugeborenen Mädchen bestimmen, es werde ihn, den Lauscher, später einmal heiraten. Der Mann will nicht mehr so lange auf seine Heirat warten und versucht, das Mädchen zu ermorden. Der Anschlag mißlingt. Das Mädchen wird gerettet und behält von der Verwundung eine Narbe zurück. Nach Jahren kommt der noch immer unverheiratete Mann an den gleichen Ort, verliebt sich in das herangewachsene Mädchen und heiratet es. Als er eines Tages die Narbe entdeckt und seine Frau ihre Geschichte erzählt, stellt er fest, daß die Prophezeiung doch in Erfüllung gegangen ist.

Kehren wir zum Abschluß noch einmal zu den osteuropäischen Sagen vom Schicksal zurück. Dieser ausgedehnte Komplex von innerlich verwandten und zusammengehörigen Sagen hat in ähnlicher Weise wie die Schicksalsmärchen auch andere Erzählungen in seinen Bann zu schlagen vermocht. Das Motiv der Schicksalsbestimmung hat sich aus den Sagen losgelöst und ist auf andere Erzählungen übergegangen, die ursprünglich nichts mit diesem ganzen Bereich gemein hatten. Dies trifft beispielsweise auf die Erzählung vom „König Midas mit den Eselsohren“ zu. In vereinzelten Varianten dieser schon in der Antike nachweisbaren Erzählung hat sich das Schicksalsmotiv in der Einleitung angesiedelt; eine griechische Fassung aus Zakynthos hat z. B. folgenden Inhalt: 
Einem König war bei seiner Geburt von den Moiren vorausgesagt worden, er solle Bocksohren haben, und wenn sein Volk dies erführe, so müsse er alsbald sterben. Der König trug immer einen Schleier, damit niemand die Ohren sehen könne. Nur sein Barbier wußte um das Geheimnis, und als es der gar nicht mehr aushalten konnte, grub er ein Loch und teilte dem Erdboden das streng gehütete Geheimnis mit. Ein junger Bursche kam an der Stelle vorbei, schnitt ein Schilfrohr ab und machte daraus eine Flöte. Als er darauf blies, ertönte es: „Der König, der fünffach verschleierte, hat Bocksohren!" Darauf mußte der König sterben. ${ }^{1}$

Wenn wir uns abschließend den modernen Aspekten zuwenden, die die Erzählungen vom vorherbestimmten Schicksal zeigen, so ist zuvor festzustellen, daß der Volksglaube von den Schicksalsfrauen in Osteuropa heute im Abnehmen begriffen, ja daß er in einigen Ländern bereits nahezu zur historischen Erscheinung geworden ist. Erwartungsgemäß ist dieses Schwinden der Glaubensvorstellungen nicht ohne Einfluß auf die entsprechenden Volkserzählungen geblieben. Tatsächlich ist zu beobachten, daß die dämonischen Schicksalskünder allmählich auch aus den Erzählungen zu verschwinden beginnen. Wir können geradezu von einer Tendenz zur Entdämonisierung der Erzählungen sprechen. Die Schicksalsfrauen, die schon vorher ganz nach menschlichem Vorbild gedacht waren, werden vollends zu menschlichen Wesen: Zigeunerinnnen, wahrsagende Frauen, die Hebamme oder sonstige menschliche Gestalten übernehmen ihre Funktion. Die zweite Entwicklungstendenz, die die Schicksalserzählungen besonders nachhaltig beeinflußt hat, ist die Verchristlichung. Populäre Heiligengestalten oder Gott selbst treten als Schicksalskünder in die Erzählungen ein und verdrängen die heidnischen Dämonen. Dieser volkstümlichen Verchristlichung steht eine wohl von der Geistlichkeit gelenkte gegenüber. Dabei wird der ganze Gehalt der Erzählungen in das Gegenteil verkehrt und gezeigt, daß sich die Schicksalssprüche der heidnischen Gestalten nicht erfüllen und das Wort Gottes eine den Schicksalsfrauen überlegene Macht ist. Durch diese entscheidende Umwandlung werden die Sagen an ihrer Wurzel getroffen, der Mensch atmet erleichtert auf und fürchtet nicht länger den unheimlichen Zwang, den die Schicksalsmächte auf ihn ausüben. Ein Zeugnis für diese Befreiung aus dem Glauben an Vorherbestimmung soll zum Abschluß noch

1 Bernhard Schmidt, Griechische Märchen, Sagen und Volkslieder, Leipzig I 877, S. $70 \mathrm{f}, \mathrm{Nr} .4$. 
vorgeführt werden. Es handelt sich bei dem Beispiel um eine Variante der Schicksalssage vom prophezeiten Tod durch einen Blitz. Diese Sage ist in ganz Osteuropa weit verbreitet und auch aus Schweden und Finnland belegt. Die folgende Variante ist bei den Slowenen in den Julischen Alpen (an der österreichisch-jugoslawischen Grenze) aufgezeichnet worden. Sie lautet:

Eine Hebamme wurde einmal nachts zur Hilfeleistung bei einer Entbindung gerufen. Als sie nach der Geburt des Kindes, eines Knaben, am Bett der Wöchnerin saß, bemerkte sie auf der Straße vor dem Fenster drei weiße, schön und hell gekleidete Frauen, die miteinander redeten. Sacht schlich sie näher, um das Gespräch zu belauschen. Die erste sagte: „Er wird ein Priester werden." — „Nein", entgegnete die zweite, ,,im Kriege wird er seinen Tod finden." - „Schwestern, erreicht das Kind sein I8. Lebensjahr, dann wird es der Blitz erschlagen", raunte die dritte der Rojenicen. Der Knabe erhielt in der Taufe den Namen Andrej. Beim Patenschmaus waren alle sehr heiter; nur die Hebamme blieb wortkarg. Als man sie fragte, warum sie so traurig sei, erzählte sie dem Vater des Kindes und den Gästen, was sie in jener Nacht erlauscht hatte. Nachdenklich verabschiedeten sich die Eingeladenen; es ist ja bekannt, daß die dritte Schicksalsgöttin die Bestimmende ist. Kurze Zeit darauf erkrankte Andrejs Vater. Er fühlte sich seinem Ende nah und vertraute das Geheimnis der Hebamme seiner Frau an, dann verschied er. Die Sorge für ihr Kind war fortan die einzige Lebensaufgabe der Witwe. - Als Andrej siebzehn Jahre alt wurde, verfiel die Mutter auf den Gedanken, für ihn ein so festes Haus bauen zu lassen, daß es selbst der Blitz nicht zu zerstören vermöchte. Auf breiten Fundamenten wurde ein mächtiges Gewölbe von Quadersteinen aufgeführt; darauf wurde ein ebenso starkes zweites gemauert; dann folgte ein drittes, viertes, bis schließlich im ganzen neun Gewölbe übereinander errichtet waren. Als der Sohn nach dem Zweck dieses Riesenbaues fragte, erklärte die Mutter, daß das Haus zu seinem Schutz gegen ein grausames Schicksal dienen sollte. Unweit davon ließ die Witwe zur Erinnerung an ihren toten Mann einen Denkstein und vor diesen einen Betstuhl setzen. Dort hielt sie allabendlich mit Andrej ihre Andacht. Am Vorabend des verhängnisvollen Tages sagte sie zu ihrem Sohn: „Morgen wirst du I 8 Jahre alt. Was die dritte Rojenica prophezeit hat, mein Kind, dürfte bald eintreffen. Es fällt mir schwer; aber um dein Leben zu retten, mußt du von nun an in dem festen Gewölbe weiterleben und darfst es nie verlassen. Ich werde immer bei dir sein, um dich zu trösten. Jetzt komm noch einmal zum Gedenkstein deines Vaters; laß uns dort zum letzten Male zusammen beten!“ Als sie vor dem Kruzifix standen, sprach Andrej: „,Mutter, sei nicht bange! Ich vertraue fest auf Gott. Unter seiner Bestimmung stehe ich. Sein Wille geschehe!" Im Gebet versunken bemerken beide nicht, daß sich der Himmel plötzlich dicht umzog. Schwere schwarze Wolken ballten sich zusammen, grelle Blitze durchzuckten die Luft, Donnerrollen erschütterte die Erde; und mitten in fürchterlichem Unwetter 
fuhr ein Feuerstrahl in das Haus mit den neun Gewölben und vernichtete es völlig. Nur Schutt und Asche blieben zurück. (Der Junge aber blieb unversehrt). ${ }^{1}$

Wir sind am Ende dieses kleinen Rundganges durch die Sagen vom vorherbestimmten Schicksal angelangt. Meine Absicht war es, Sie in die faszinierende Welt dieser Sagen einzuführen und ich wäre froh, wenn die dargebotenen Beispiele dazu beitragen konnten, Ihnen einen Einblick in die sonst wenig bekannten volkstümlichen osteuropäischen Vorstellungen vom Schicksal zu vermitteln.

${ }^{I}$ Anton von Mailly, Sagen aus Friaul und den Fulischen Alpen, Leipzig 1922, S. 19 ff., Nr. 20. 